\title{
CCV. THE SUGARS OF URINE.
}

\section{THE CHEMICAL NATURE OF THE FERMENTABLE SUGAR OF NORMAL AND STARVATION URINE.}

\author{
By EDWARD STAUNTON WEST AND ALEXANDER STEINER. \\ From the Laboratory of Biological Chemistry, Washington \\ University School of Medicine, Saint Louis, Missouri.
}

(Received August 2nd, 1932.)

That a part of the sugar of normal urine is fermentable or rather yeastutilisable seems to have been established by the work of Van Slyke and Hawkins [1929], Peterson and West [1929], West and Peterson [1932], and West, Lange and Peterson [1932]. These last workers have also uniformly found it in starvation urines. Harding and Selby [1931] observed fermentable sugar in urines after carbohydrate and fruit diets but not in starvation urines. The failure of Harding and Selby to find fermentable sugar in starvation urines has been discussed in the second paper of this series and shown to be due probably to their analytical procedure.

The methods of analysis used by all the above workers indicate only that a part of the reducing power of urine is lost as a result of yeast action. They do not prove that a sugar, fermentable in the sense of yielding carbon dioxide and alcohol, is present. In fact, Lund and Wulf [1926] failed to observe any carbon dioxide production from normal urine when treated with pure yeast in a Barcroft manometer. These workers conclude that glucose is not a constituent of normal urine. Various investigators have prepared osazones of the urinesugars in attempts to prove or disprove the presence of glucose. Of these Geelmuyden [1915], Höst [1923] and Patterson [1926] have reported failures to isolate $d$-phenylglucosazone from normal urines. Hassan [1928] reported the preparation of typical glucosazone crystals from many, but not all, normal urines. Greenwald, Gross and McGuire [1927] have called attention to the possibility of forming glucosazone from non-fermentable sugar derivatives of urine, especially the anhydro-sugars. Everett and Sheppard [1932] have pointed out some of the sources of error in attempts to identify glucosazone crystals among the osazones formed from urine-sugars.

It should be emphasised that neither the production of carbon dioxide under the action of yeast nor the isolation of glucosazone establishes the presence of glucose in urine. Glucose, fructose, mannose and some of the 
anhydro-sugars give rise to glucosazone, and glucose, fructose, mannose and some disaccharides are fermented by yeast.

The failure of Lund and Wulf to obtain carbon dioxide production in their fermentation of normal urine may be related to two factors. They used $1 \mathrm{cc}$. of undiluted, untreated urine and added $0.5 \mathrm{cc}$. of a $1 \%$ phosphoric acid solution to it before fermentation to adjust the $p_{\mathrm{H}}$. Undiluted, untreated urine contains a large amount of non-sugar material which may inhibit yeast action on small quantities of sugar. Also their adjustment of $p_{\mathrm{H}}$ was uncertain, doubtless varying from sample to sample as the buffer content of the urines varied. They make no statements as to the $p_{\mathrm{H}}$ of any of their samples. Some normal urines may contain only 5-8 mg. of glucose per $100 \mathrm{cc}$. and in such cases they were working with $0 \cdot 05-0.08 \mathrm{mg}$. of sugar. This quantity would produce from 11 to $17 \mathrm{~mm} .^{3}$ of carbon dioxide which may have been absorbed by the buffers of their solutions without registering on the manometer.

Because of the unsatisfactory state of the problem, resulting from inadequate methods, the writers have tried a different approach in an attempt to establish the presence or absence of glucose in both normal and starvation urines. It is a well-established fact that sugars are fermented at different rates and it is possible, by use of the Warburg apparatus, to obtain a characteristic curve of carbon dioxide production for each fermentable sugar. In order that such a procedure may be successfully applied to urine it is advisable that the urine be treated to remove most of the nitrogenous and other non-sugar constituents and that the $p_{\text {H }}$ of the solution be accurately adjusted. Also the solution fermented should contain much more sugar than undiluted, normal urine. These demands have been met in the following way. $\mathrm{HgSO}_{4}-\mathrm{BaCO}_{3}$ filtrates of large quantities of urine $(800 \mathrm{cc}$.) were prepared according to the procedure already outlined [West and Peterson, 1932]. These filtrates were evaporated to dryness, taken up in a small quantity of $\mathrm{H}_{2} \mathrm{O}$ and precipitated with alcohol to remove salts. The alcoholic solutions were evaporated to dryness, taken up in $\mathrm{H}_{2} \mathrm{O}$ and again precipitated with $\mathrm{HgSO}_{4}-\mathrm{BaCO}_{3}$. Evaporation of the filtrates and precipitation with alcohol were repeated and the alcoholic solution, free of salts, was evaporated to dryness. The residue was then taken up in 0.15 $\mathrm{M} \mathrm{NaH}_{2} \mathrm{PO}_{4}$. By this procedure a sugar solution of the desired sugar concentration and $p_{\mathrm{H}}$ and relatively free from nitrogenous and other nonsugar substances is obtained. Suitable quantities of these solutions were fermented with washed yeast in the Warburg apparatus and the rate of carbon dioxide formation observed. Urine-sugar residues were also taken up in $0.5 \mathrm{~N} \mathrm{H}_{2} \mathrm{SO}_{4}$ and hydrolysed before running fermentation curves. Solutions of glucose, fructose and mannose of the same reduction equivalents as the fermentable sugar of the urine samples were fermented in exactly the same manner simultaneously. In this way a series of curves of the fermentable hexoses was obtained under the same conditions of concentration (reduction equivalent), $p_{\mathbf{H}}$ and temperature as for the fermentable sugar of the urine samples. 


\section{Experimental.}

\section{Urine samples.}

The daily fermentable sugar excretion of the three subjects who supplied urine for the following work was normal, there being no indication of a low renal threshold. For the collection of normal urine samples the subject was placed on a sugar- and fruit-free diet for 2 days, the sample being taken the second day. This was done to eliminate the possibility of sugar appearing in the urine from the ingestion of fruit juices etc. as found by Harding and Selby [1931]. For starvation urines the subject ate supper and began collecting the sample the next day about 15 hours after the last meal, which was sugar- and fruit-free. Urines were preserved during collection and for the short period before use by means of toluene.

\section{Preparation of urine-sugars for fermentation.}

Two portions of $400 \mathrm{cc}$. of urine are precipitated as follows and the filtrates combined.

400 cc. of urine and 1800 cc. of $\mathrm{H}_{2} \mathrm{O}$ are placed in a 6-litre Florence flask. To this are added 600 cc. of a saturated solution of $\mathrm{HgSO}_{4}$ in $10 \% \mathrm{H}_{2} \mathrm{SO}_{4}$ (about $28 \mathrm{~g}$. of $\mathrm{HgSO}_{4}$ per 100 cc.) with rapid mixing. Solid precipitated $\mathrm{BaCO}_{3}$ is then quickly added and the solution neutralised as rapidly as possible by continual shaking and addition of further portions of $\mathrm{BaCO}_{3}$. The reaction is complete when $\mathrm{CO}_{2}$ ceases to be evolved and the solution no longer reddens blue litmus. The precipitate is filtered off on washed papers with suction, and the filtrate (4000-5000 cc.) is treated with 2 cc. of conc. $\mathrm{H}_{2} \mathrm{SO}_{4}$ per litre. Mercury is removed from the filtrate by $\mathrm{H}_{2} \mathrm{~S}$ and the latter is blown off with air. The solution is then neutralised with pure $\mathrm{BaCO}_{3}$ and filtered at the pump through washed papers. A few drops of conc. $\mathrm{H}_{2} \mathrm{SO}_{4}$ are added to the filtrate and a little $\mathrm{NaH}_{2} \mathrm{PO}_{4}$ so that it reacts acid to litmus and alkaline to Congo red. A little toluene is added to the solution which is then evaporated to dryness at a temperature of $30-35^{\circ}$ under reduced pressure, with a stream of $\mathrm{CO}_{2}$ passing through it. At intervals the evaporation is interrupted and more $\mathrm{NaH}_{2} \mathrm{PO}_{4}$ added, if necessary, to maintain a faintly acid reaction. The residue is taken up in about 50 cc. of $\mathrm{H}_{2} \mathrm{O}$, precipitated with $1000 \mathrm{cc}$. of alcohol, and after standing overnight the solution is filtered and the alcohol evaporated in vacuo at $30-35^{\circ}$. The residue is taken up in $165 \mathrm{cc}$. of $\mathrm{H}_{2} \mathrm{O}$ and precipitated with $45 \mathrm{cc}$. of the $\mathrm{HgSO}_{4}$ reagent, neutralised with $\mathrm{BaCO}_{3}$ and excess mercury removed with $\mathrm{H}_{2} \mathrm{~S}$ in the usual way. The filtrate is neutralised with $\mathrm{BaCO}_{3}$ and the reaction made faintly acid with a drop or two of conc. $\mathrm{H}_{2} \mathrm{SO}_{4}$ and a little $\mathrm{NaH}_{2} \mathrm{PO}_{4}$ and the solution evaporated to dryness as in the first case. The residue is taken up in 25 cc. of $\mathrm{H}_{2} \mathrm{O}$ and precipitated with $500 \mathrm{cc}$. of alcohol. After standing overnight the solution is filtered and divided into two equal parts. Both are evaporated to dryness in vacuo at $30-35^{\circ}$. One residue is taken up in 25 cc. of $0.5 \mathrm{~N} \mathrm{H}_{2} \mathrm{SO}_{4}$ and hydrolysed in a boiling water-bath for 5 hours. The solution 
is then diluted to $300 \mathrm{cc}$. with $\mathrm{H}_{2} \mathrm{O}$, neutralised with pure $\mathrm{BaCO}_{3}$, filtered through washed papers at the pump, the precipitate washed with 50 cc. of $\mathrm{H}_{2} \mathrm{O}$ and the washings combined with the filtrate. The solution is then rendered faintly acid with $\mathrm{NaH}_{2} \mathrm{PO}_{4}$ and evaporated to dryness in vacuo in the usual way. The residue is taken up in about $20 \mathrm{cc}$. of $\mathrm{H}_{2} \mathrm{O}$, precipitated with $300 \mathrm{cc}$. of alcohol, filtered, and the alcoholic solution evaporated in vacuo as above. The hydrolysed residue remaining is taken up in 15-20 cc. of $0 \cdot 15 \mathrm{M} \mathrm{NaH}_{2} \mathrm{PO}_{4}$ as is also the other residue which has not been hydrolysed. Fermentable sugar is then determined in the solutions, after proper dilution, by the method of West and Peterson [1932]. This generally amounts to $0.5 \mathrm{mg}$. or more per cc. of solution.

In order to determine whether the fermentable sugar might arise from the filter-paper used, a water blank was run through in the same way as urine. No fermentable sugar was found either before or after hydrolysis.

The $\mathrm{HgSO}_{4}-\mathrm{BaCO}_{3}$ filtrates are kept slightly acid during evaporation, otherwise the alkalinity produced as the solutions concentrate may bring about interconversion of related sugars.

There is considerable loss of sugar in the process, probably referable to retention in the precipitates and possibly to esterification with the phosphate added during evaporation. When only one $\mathrm{HgSO}_{4}$ precipitation is performed and evaporation is done without phosphate, the loss is small.

The nitrogen content of such solutions generally amounts to $0.5 \mathrm{mg}$. or less per cc. or about $10 \mathrm{mg}$. total $\mathrm{N}$ in the entire solution as contrasted with about $4000 \mathrm{mg}$. in the original untreated urine. It has been found desirable to use the double precipitation with $\mathrm{HgSO}_{4}-\mathrm{BaCO}_{3}$ in order more efficiently to remove non-sugar materials which interfere with and inhibit fermentation.

\section{Fermentation in the Warburg apparatus.}

The fermentations were done in the usual way. Vessels with two side-arms were used. Three series were set up in which the urine-sugars were fermented simultaneously with glucose, fructose and mannose, all made up in $0.15 M$ $\mathrm{NaH}_{2} \mathrm{PO}_{4}$ solution. These control sugar solutions were prepared so that there was present in $0.2 \mathrm{cc}$. a quantity of sugar equivalent in reduction value to the fermentable urine-sugar. The arrangements were as follows. 1-2 cc. of the urine-sugar solution were placed in the vessel. Sufficient $0.15 \mathrm{M} \mathrm{NaH}_{2} \mathrm{PO}_{4}$ was then added to bring the volume to $3 \mathrm{cc} .0 \cdot 2 \mathrm{cc}$. of a $20 \%$ suspension of washed Fleischman's yeast was placed in one side-arm, and $0.2 \mathrm{cc}$. of the control sugar (glucose, fructose or mannose) in the other. The controls of glucose, fructose and mannose were prepared in the following way. $0.2 \mathrm{cc}$. of the sugar solution was placed in the vessel with $2.8 \mathrm{cc}$. of $\mathrm{NaH}_{2} \mathrm{PO}_{4}$ solution. $0.2 \mathrm{cc}$. of the sugar solution was also placed in one side-arm, and $0.2 \mathrm{cc}$. of the yeast suspension in the other. The vessels, with manometers, were then equilibrated with nitrogen and placed in the constant temperature bath at $30^{\circ}$. A thermobarometer containing $3 \cdot 4 \mathrm{cc}$. of $0 \cdot 15 \mathrm{M} \mathrm{NaH}_{2} \mathrm{PO}_{4}$ solution was placed in the bath simultaneously. After temperature equilibrium was reached the yeast 
was tipped into the vessels and readings taken at 5 minute intervals throughout the period of rapid fermentation and at 10 minute intervals thereafter. Upon completion of the first fermentation the sugar solutions in the side-arm were tipped into the vessels and readings taken as before.

A fermentation was performed in which one side-arm contained saturated $\mathrm{Ba}(\mathrm{OH})_{2}$. A large quantity of $\mathrm{BaCO}_{3}$ separated indicating that the gas produced from the fermentable urine sugar was carbon dioxide.

\section{Discussion.}

Figs. 1-8 summarise the results obtained on two normal urines from different subjects and similarly two starvation urines. The curves are plotted in pairs showing simultaneous fermentation of urine-sugar and an equivalent concentration (from reduction value) of glucose, fructose and mannose. The second parts of the curves represent the fermentations of sugar (equivalent to that in the original urine and control sugar solutions) added to the previously fer-

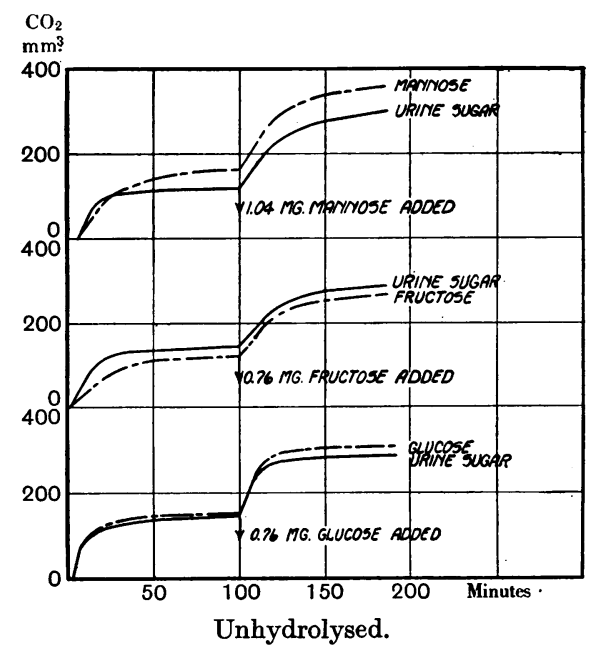

Fig. 1. Normal urine-I. Sugar- and fruit-free diet. Reducing power of sample $=0.758 \mathrm{mg}$. glucose.

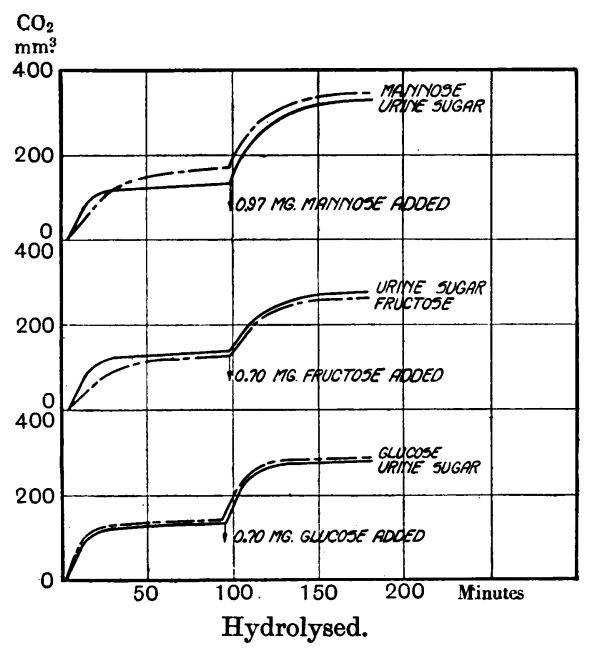

Fig. 2. Normal urine-I. Sugar- and fruit-free diet. Reducing power of sample $=0.70 \mathrm{mg}$. glucose.

mented urine and control sugar solutions. This was done to determine whether there were non-fermentable substances in the urine samples which interfered with the rate of fermentation. It will be seen that the sugar added to the previously fermented urine-sugar solution fermented essentially similarly to that added to the fermented control.

In all cases the curves of fermentation of the urine-sugar follow closely those of an equivalent quantity of glucose throughout the period of rapid fermentation, and in three cases of normal urine they run closely parallel throughout. On the other hand, the fermentation curves of fructose and mannose show entirely different rates of carbon dioxide production in all cases. 
Experiments on maltose were also carried out and it was found to ferment much more slowly than the urine-sugar. We interpret these findings as evidence that

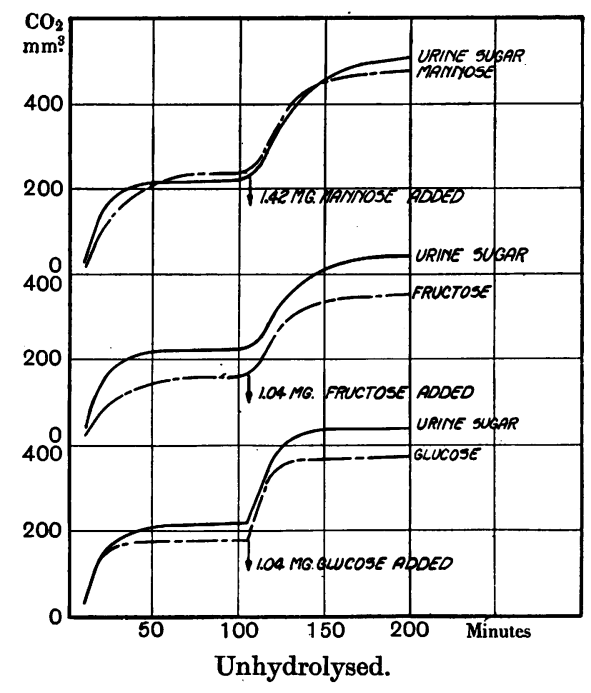

Fig. 3. Starvation urine-I. Reducing power of sample $=1.04 \mathrm{mg}$. glucose.

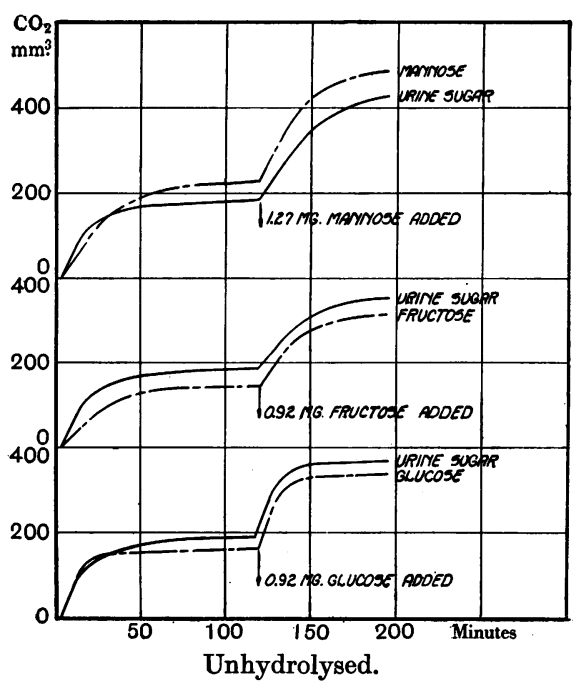

Fig. 5. Normal urine-II. Sugar- and fruit-free diet. Reducing power of sample $=0.92 \mathrm{mg}$. glucose.

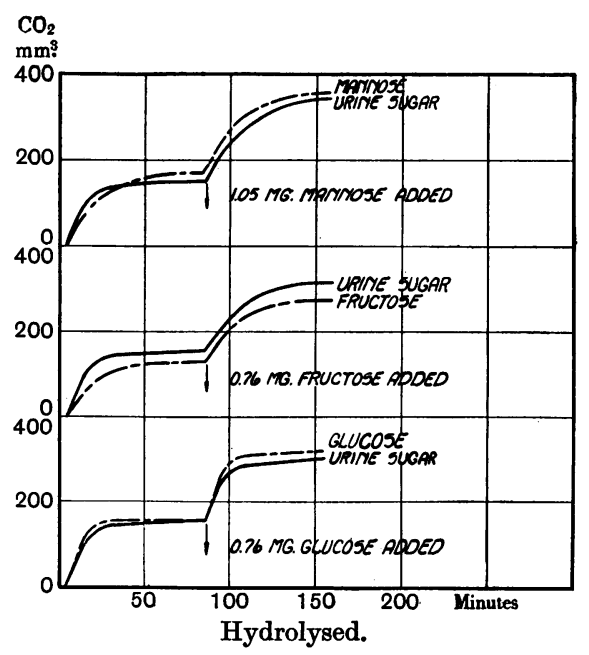

Fig. 4. Starvation urine-I. Reducing power of sample $=0.76 \mathrm{mg}$. glucose.

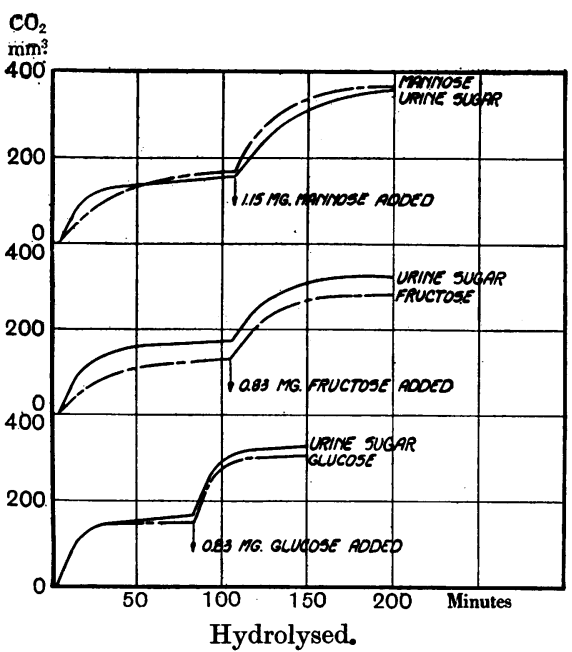

Fig. 6. Normal urine-II. Sugar- and fruit-free diet. Reducing power of sample $=\mathbf{0 . 8 3} \mathrm{mg}$. glucose.

both normal and starvation urines contain fermentable sugar in the strict sense of the term and that this sugar is glucose.

The divergence found in the final stages of fermentation in some cases may be referable to several factors. Generally the urine-sugar curve rises higher and 
with a more gradual slope than the glucose curve. This may possibly be due to slow decarboxylation of an organic acid, or the slow fermentation of a disaccharide or to the stimulating effect of certain non-sugar substances upon the yeast. There may also have been slight errors in determining the fermentable sugar of the urine-sugar solutions. The slopes of the curves, however, do not indicate that this is an important factor. We have found that the addition of a little $\left(\mathrm{NH}_{4}\right)_{2} \mathrm{SO}_{4}$ or pyruvate to a glucose solution gives curves similar in form to these elevated urine-sugar curves, and are inclined to consider them, in part at least, due to the effect of such or similarly acting substances.

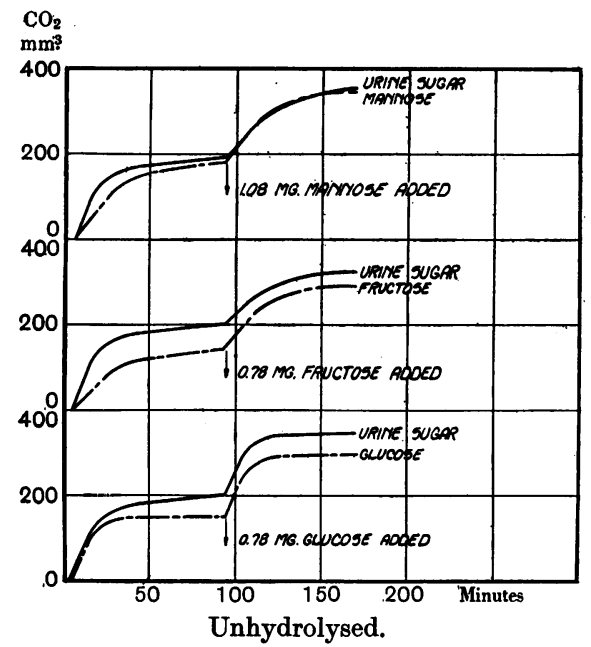

Fig. 7. Starvation urine-II. Reducing power of sample $=0.78 \mathrm{mg}$. glucose.

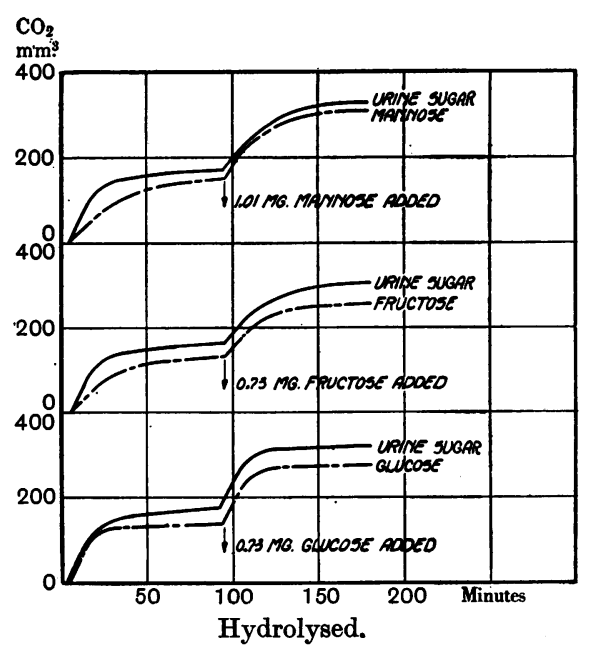

Fig. 8. Starvation urine-II. Reducing power of sample $=0.73 \mathrm{mg}$. glucose.

It should be pointed out that pyruvate is not decarboxylated by yeast under the conditions of our experiments but if mixed with glucose slightly more $\mathrm{CO}_{2}$ is evolved than from the glucose alone. The effect was removed in two cases by hydrolysis and not in another. From this it seems unlikely that it can be referred to the presence of a slowly fermentable disaccharide. Sugars of this nature would not be expected in the urines we used unless of an endogenous origin.

The glucose in urine found by us probably did not arise from the hydrolysis of anhydro-sugars referred to by Greenwald, Gross and McGuire [1927]. These should not exist in either normal urines from a sugar- and fruit-free diet, or starvation urines.

\section{Summary.}

Evidence is presented that both normal and starvation human urines contain fermentable sugar in the strict sense of the term and that this sugar is glucose. This evidence is based upon the fermentation rates of purified urine- 
sugars in the Warburg apparatus simultaneously with glucose, fructose and mannose controls. The rate of carbon dioxide production from the urine-sugars parallels that from glucose but not those from mannose or fructose.

The writers are indebted to Mr R. C. Norris for technical assistance.

\section{REFERENCES.}

Everett and Sheppard (1932). J. Biol. Chem. 96, 431.

Geelmuyden (1915). Morsk. Mag. Laegevidenskaben, 13, 985.

Greenwald, Gross and McGuire (1927). J. Biol. Chem. 75, 491.

Harding and Selby (1931). Biochem. J. 25, 1815.

Hassan (1928). Biochem. J. 22, 1332.

Höst (1923). J. Metabol. Res. 4, 315.

Lund and Wulf (1926). Biochem. J. 19, 538.

Patterson (1926). Biochem. J. 20, 651.

Peterson and West (1929). Amer. J. Physiol. 90, 470.

Van Slyke and Hawkins (1929). J. Biol. Chem. 83, 51.

West and Peterson (1932). Biochem. J. 26, 1720.

- Lange and Peterson (1932). Biochem. J. 26, 1728. 